\title{
SIRT1 Knockdown Enhances the Differentiation of Human Embryonic Stem Cells into Pancreatic $\beta$ Cells
}

\author{
Nan-Hee Seo, Hwa-Ryung Song, and Myung-Kwan Han \\ Dept. of Microbiology, Jeonbuk National University Medical School, Jeonju 54896, Korea
}

\begin{abstract}
Nicotinamide is used to maturate pancreatic progenitors from embryonic stem cells (ESCs) into insulinproducing cells (IPCs). It has been known that nicotinamide inhibits the enzymatic activity of SIRT1, an NAD ${ }^{+}$-dependent deacetylase. Here we show that SIRT1 knockdown enhances the differentiation of human ESCs into IPCs. SIRT1 knockdown enhances the clustering size of IPCs and the expression of pancreatic genes including c-peptide, pancreas/duodenum homeobox protein 1 (PDX1), insulin, somatostatin, glucagon and Nkx6.1 in human ESC-derived IPCs. In addition, We found that IPCs differentiated from SIRT1 knockdowned human ESCs have more zinc compared to those from control human ESCs. Our data suggest that SIRT1 negatively regulates the differentiation of $\beta$ cells from human ESCs.
\end{abstract}

Key words : SIRT1, Human embryonic stem cells, Pancreatic $\beta$ cells

\section{INTRODUCTION}

Embryonic stem cells (ESCs) have been regarded as a useful tool to research embryogenesis at the cellular level and a promising tool for cell replacement therapy because of their unlimited proliferative properties and differentiation potential into all kind cell type of the body (Thomson et al., 1998; Doss et al., 2004; Nishikawa et al., 2007; Takahashi \& Yamanaka, 2006).

Type I diabetes results from autoimmune destruction of $\beta$ cells in the pancreatic islet. The destruction could be repaired by new $\beta$ cell transplantation. It has been reported that cadaveric human islet transplantation to type I diabetic patients was effective to treat diabetes for 5 years (Bellin et al., 2012). However, this strategy has a limitation that islet donors are very scare. Thus, the derivation of $\beta$ cells from ESCs that have an unlimitedly proliferating capacity could be an alternative to the preparation of a transplantable cell source for diabetic patients.

ESCs can be differentiated into pancreatic progenitors via the definitive endoderm with efficiencies (Kroon et al., 2008; Rezania et al., 2012). These cells can further be differentiated into functional $\beta$ cells, insulin producing cells (IPCs) (Kroon et al., 2008; Rezania et al., 2012). ESCs can also be differentiated into IPCs via nestin-positive progenitor route (Lumelsky et al., 2001; Mao et al., 2009). The resulting IPCs from both protocols shared many similar features with pancreatic islet cells, but not mature, functional $\beta$ cells (Wei et al., 2013).

SIRT1 is an NAD+-dependent deacetylase involved in numerous fundamental cellular processes including gene silencing, DNA repair, and metabolic regulation (Baur et

\footnotetext{
Manuscript received October 21, 2019, Received in revised form November 12, 2019, Accepted November 25, 2019

${ }^{\dagger}$ Corresponding Author : Myung-Kwan Han, Dept. of Microbiology, Jeonbuk National University Medical School, Jeonju 54896, Korea. Tel: +82-63270-3106, Fax: +82-63-274-9833, E-mail: iamtom@jbnu.ac.kr

This is an Open Access article distributed under the terms of the Creative Commons Attribution Non-Commercial License (http:// creative-commons.org/licenses/by-nc/3.0) which permits unrestricted non-commercial use, distribution, and reproduction in any medium, provided the original work is properly cited.
} 
al., 2010; Donmez \& Guarente, 2010; Haigis \& Sinclair, 2010). SIRT1 activity is inhibited by nicotinamide, which binds to a specific receptor site (Avalos et al., 2005). Nicotinamide has been known to maturate pancreatic progenitors from ESCs into IPCs. These suggest that control of SIRT1 activity affect the differentiation of ESCs into IPCs. Thus, in this study we examined whether SIRT1 knockdown affect the differentiation of human ESCs into IPCs.

\section{MATERIALS AND METHODS}

\section{Human ESC culture}

The human ESC line H9 (WiCell, WI, USA) were cultured on mitomycin C (10 $\mu \mathrm{g} / \mathrm{mL})$-treated mouse embryonic fibroblasts in DMEM/F12 containing $0.1 \mathrm{mM} \quad \beta$ mercaptoethanol, $1 \%$ NEAA, $0.1 \%$ penicillin/streptomycin, $20 \%$ knockout serum replacement (Invitrogen, Carlsbad, CA, USA), $1 \mathrm{mM}$ glutamax (Gibco, Carlsbad, CA, USA) and $10 \mathrm{ng} / \mathrm{mL}$ basic fibroblast growth factor. $\mathrm{H} 9$ colonies were mechanically transferred every $4-5$ days.

\section{Differentiation of IPCs from human ESCs}

H9 was differentiated into IPCs via the definitive endoderm by the method described by Rui Wei et al. (2013) with some modification. hESCs of small clumps were plated on matrigel (1:50, BD Biosciences)-coated dishes and cultured with DMEM/F12 (Invitrogen, Carlsbad, CA, USA) supplemented with $100 \mathrm{ng} / \mathrm{mL}$ activin A (R\&D), 1 $\mu \mathrm{M}$ wortmannin (Sigma, St. Louis, MO, USA), 1\% N2 (Invitrogen) and 1\% B27 (Invitrogen) for 4 days. The plated cells were induced into pancreatic progenitor cells under culture in IMDM/F12 supplemented with $2 \mu \mathrm{M}$ retinoic acid (Sigma), $20 \mathrm{ng} / \mathrm{mL}$ fibroblast growth factor 7 (Peprotech, Rocky Hill, NJ, USA), 50 ng/mL Noggin (Peprotech), $0.25 \mu \mathrm{M}$ KAAD-cyclopamine (Calbiochem, San Diego, CA, USA) and 1\% B27 for 4 days. The pancreatic progenitor cells were expanded in high glucose DMEM (Welgene, Korea) supplemented with $50 \mathrm{ng} / \mathrm{mL}$ endothelial growth factor (Peprotech), 1\% ITS (Sigma), and 1\% N2 for 5 days. The pancreatic progenitor cells were developed into IPCs in low glucose DMEM (Invitrogen) /F12 (1:1) supplemented with $1 \%$ ITS, $10 \mathrm{ng} / \mathrm{mL}$ bFGF and $50 \mathrm{ng} / \mathrm{mL}$ exendin-4 (Sigma) for 9 days. The IPCs were maturated by detaching with $0.05 \%$ trypsin-EDTA and seeding to ultralow attachment 6-well plates (Corning, Tewksbury, MA, USA) for 3 days.

\section{Immunofluorescence}

IPCs were fixed in 4\% paraformaldehyde in PBS for 20 $\mathrm{min}$ at room temperature. The cells were blocked for 1 hour at room temperature with $10 \%$ normal goat serum in PBS containing $0.1 \%$ Triton X-100. The cells were stained with primary antibodies and Alexa Fluor 488 or Alexa 594 nm-conjugated secondary antibodies in PBS containing $1 \%$ BSA and $0.3 \%$ Triton X-100. The nuclei was stained with DAPI. The following antibodies and dilutions were used : 1:100; mouse anti-pancreatic and duodenal homeobox 1 (PDX1) (Santa Cruz, Dallas, TX, USA), 1:100; rabbit antic-peptide (Cell signaling, Danvers, MA, YSA), 1:100, goat anti-Nkx6.1 (Santa Cruz), 1:100; TRITC-conjugated goat anti-rabbit IgG (Sigma), anti-goat IgG (Alexa fluorescence 488) (Abcam, Cambridge, UK), goat anti-mouse IgG (Alex fluorescence 594) (Abcam, Cambridge, UK) and goat antimouse (Alexa fluorescence 488) (Abcam, Cambridge, UK).

\section{Dithizone (DTZ) staining}

$10 \mathrm{mg} / \mathrm{mL}$ Dithizone (DTZ, Sigma) in dimethyl sulfoxide (DMSO) was diluted to $10 \mu \mathrm{g} / \mathrm{mL}$ DTZ in PBS. IPC clusters were stained at $37^{\circ} \mathrm{C}$ for $15 \mathrm{~min}$ with the solution.

\section{Western blotting}

Cells were lysed with M-PER mammalian protein extraction reagent (Pierce, Rockford, IL, USA) supplemented with a protease inhibitor cocktail (Roche, Indianapolis, IN, USA) and a phosphatase inhibitor cocktail (Roche) on ice for 1 hour. After spin down $(10,000 \times \mathrm{g}, 10 \mathrm{~min})$, the cell 
lysates were taken from the supernatant, separated by SDS-PAGE, and transferred to PVDF membrane at $60 \mathrm{~V}$, $4^{\circ} \mathrm{C}$, overnight. The membrane was blocked with $3 \%$ skim milk in tris-buffered saline containing $0.05 \%$ tween-20 for $1 \mathrm{~h}$ and incubated with anti-SIRT1 antibody for $3 \mathrm{~h}$ at room temperature. After washing, the membrane was further incubated with horseradish peroxidase-conjugated secondary antibodies for $1 \mathrm{~h}$ at room temperature. Proteins were analyzed using an enhanced chemiluminescence detection system (TaKaRa, Japan).

\section{Production of H9 human ESCs cells expressing} SIRT1 shRNA

To establish stable H9 expressing control or SIRT1 specific shRNA, H9 human ESCs cells were infected with control or SIRT1 shRNA expressing lentiviral particles (Sigma) and selected in the presence of $1 \mu \mathrm{g} / \mathrm{mL}$ of puromycin for 1 weeks. The cells were maintained in the presence of $1 \mu \mathrm{g} / \mathrm{mL}$ of puromycin. The knockdown level of SIRT1 gene was analyzed by western blotting with antiSIRT1 antibody.

7. Quantitative real-time polymerase chain reaction (QRT-PCR)

Expression of V-maf musculoaponeurotic fibrosarcoma oncogene homolog A (MAFA), PDX1, insulin (INS), somatostain (SST) and glucagon (GCG) genes was analyzed by QRT-PCR. PCR primers for those genes were purchased from Genotech (Daejeon, Korea). Total RNA was prepared using RNA Extraction Kit (QIAGENE, Germantown, MD, USA). RNA samples were reverse transcribed with random primers using Reverse Transcription System (Power cDNA Synthesis Kit; QIAGENE). Realtime PCR was performed with $\mathrm{C} 1000$ thermal cycler (Bio Rad, Hercules, CA, USA) and SYBR Premix Ex Taq (Takara, Japan). Quantitation of expression levels of pancreatic genes was performed by a CFX96 Real-Time PCR Detection System (Bio Rad). Fold-difference was calculated using the $\triangle \mathrm{Ct}$ method normalized to GAPDH.

\section{Statistics}

Data were expressed as the mean \pm SD of at least 3 independent experiments. The difference in means between 2 groups was analyzed using the Student's $t$-test.

Primer sequences used in this study are listed in Table 1.

\section{RESULTS AND DISCUSSION}

To examine whether SIRT1 affects the cluster size of human ESC-derived IPCs, we knockdowned SIRT1 by

Table 1. The primer sets used for QRT- PCR

\begin{tabular}{ccc}
\hline Name of genes & Forward primer (5'-3') & Backward primer (5'-3') \\
\hline \hline$G C G$ & CATTCACAGGCACATTCAC & CGGCCAAGTTCTTCAACAAT \\
$S S T$ & AGCTGCTGTCTGAACCCAAC & CCATAGCCGGGTTTGAGTTA \\
$I N S$ & TGCAAGGACAAGAAGCGAAG & GAGTTCCTGTCATCCCCTGG \\
$P D X 1$ & CCCTCCTACAGCACTCCACC & CCGCTGTGTGTGTTAGGGAG \\
$M A F A$ & TCATCCGGCTCAAGCAGAAG & GTTGGCACTTCTCGCTCTCC \\
$G A P D H$ & TGCACCACCAACTGCTTAGC & GGCATGGACTGTGGTCATGAG
\end{tabular}

QRT-PCR, Quantitative real-time polymerase chain reaction; $G C G$, glucagon; $S S T$, somatostain; INS, insulin; $P D X 1$, pancreas/duodenum homeobox protein 1; MAFA, v-maf musculoaponeurotic fibrosarcoma oncogene homolog A; GAPDH, glyceraldehydes-3-phosphate dehydrogenase. 

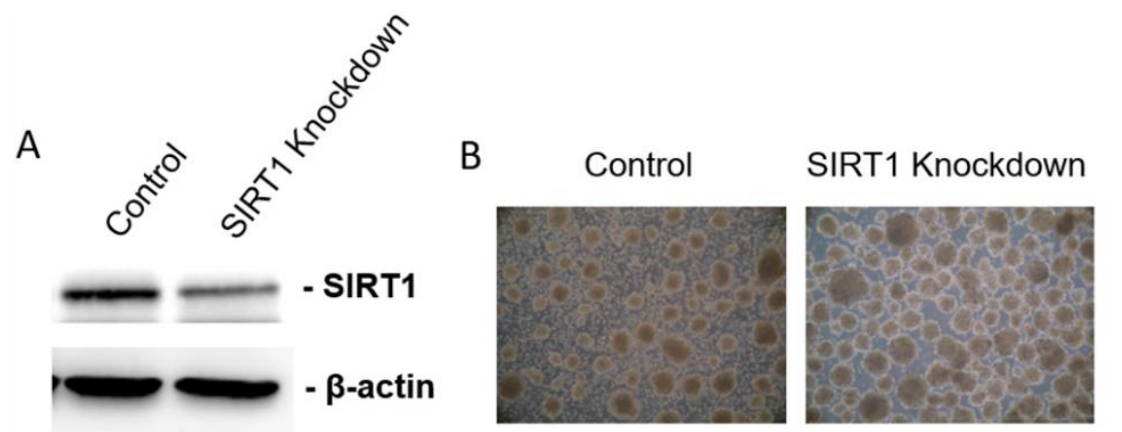

C

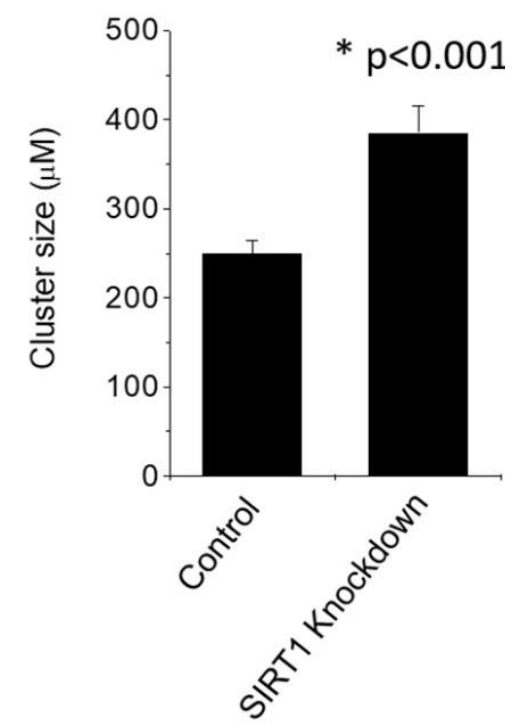

Fig. 1. SIRT1 knockdown enhances the cluster size of IPCs differentiated from human ESCs. (A) Western blot for IPCs differentiated from control and SIRT1 shRNA expressing human ESCs. Human ESCs were infected with control or shRNA expressing lentiviral particle. The cells were differentiated into IPCs as described in "Materials and Methods". (B) Photographic images of clustered IPCs differentiated from control or SIRT1 shRNA expressing human ESCs. (C) Mean diameter of IPC cluster differentiated from control or SIRT1 shRNA expressing human ESCs. IPCs, insulin-producing cells; ESCs, embryonic stem cells.

infecting human ESCs with control or SIRT1 shRNA expressing lentiviral particles. The SIRT1 expression level were decreased by the infection of SIRT1 shRNA expressing lentiviral particles (Fig. 1A). SIRT1 knockdown enhanced the cluster size of human ESC-derived IPCs by approximately $60 \%$ (Fig. 1B and 1C).

C-peptide is a substance produced by pancreatic $\beta$ cells when proinsulin splits apart and forms one molecule of $\mathrm{C}$ peptide and one molecule of insulin (Steiner et al., 1967). Since C-peptide and insulin are produced at the same rate, $\mathrm{C}$-peptide is a useful marker of insulin production. We checked the effect of SIRT1 knockdown on c-peptide expression in human ESC-derived IPCs. Expectedly, SIRT1 knockdown enhanced the expression of C-peptide in IPCs differentiated from SIRT1-knockdowned human ESCs compared to those from control human ESCs (Fig. 2). These data suggest that the inhibition of SIRT1 activity enhances the differentiation of human ESCs into IPCs.
The homeobox transcription factor NK6 homeobox 1 (Nkx6.1) is essentially required for $\beta$-cell development (Sander et al., 2000). Nkx6.1 is highly expressed during a period in which $\beta$ cells grow and differentiate (Sander et al., 2000), suggesting that Nkx6.1 expression may be involved in expansion of functional $\beta$-cell mass. Consistent with this idea, overexpression of Nkx6.1 in mature islets results in improved glucose-stimulated insulin secretion and enhanced $\beta$-cell proliferation (Schisler et al., 2008). We observed that the expression of Nkx6.1 in IPCs from SIRT1 shRNA expressing human ESCs is similar to that from control shRNA expressing human ESCs (Fig. 3). However, SIRT1 knockdown enhances and insulin in human ESC-derived IPCs (Fig. 3). These data are consistent with the data showing the enhancement of the cluster size and C-peptide expression of human ESC-derived IPCs.

QRT-PCR reaction, as shown in Fig. 4, demonstrated an enhanced expression of pancreatic genes in IPCs differentiated 


\section{Control}

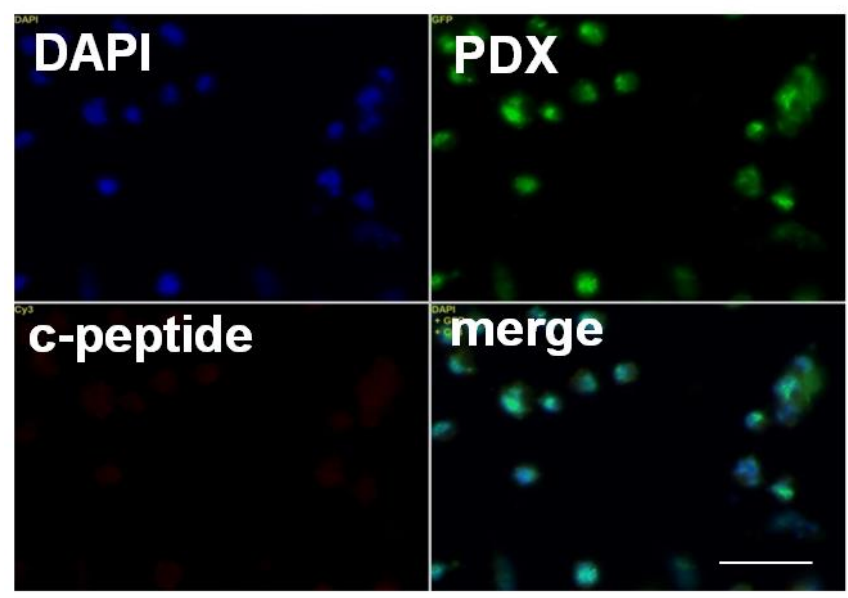

\section{SIRT1 Knockdown}

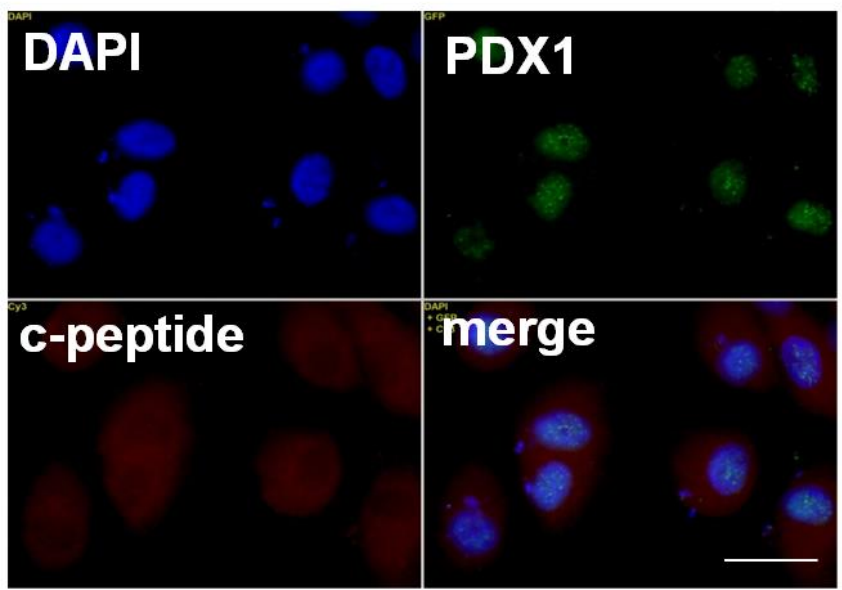

Fig. 2. The expression of PDX1 and c-peptide in IPCs differentiated from control or SIRT1 shRNA expressing human ESCs. IPCs were differentiated from control or SIRT1 shRNA expressing human ESCs as described in "Materials and Methods". The cells were stained with anti-PDX1 and anti-c-peptide antibodies, and Alexa 594 conjugated secondary antibody. The nuclei was stained with DAPI. PDX1, pancreas/duodenum homeobox protein 1 IPCs, insulin-producing cells; ESCs, embryonic stem cells.

from SIRT1 shRNA expressing human ESCs compared to those from control shRNA expressing human ESCs. SIRT1 knockdown enhanced the transcription factors, PDX1 and
MAFA, by four times in human ESC-derived IPCs (Fig. 4). The expression of the growth factors, glucagon, insulin and somatostatin, were highly enhanced in IPCs from

\section{Control}

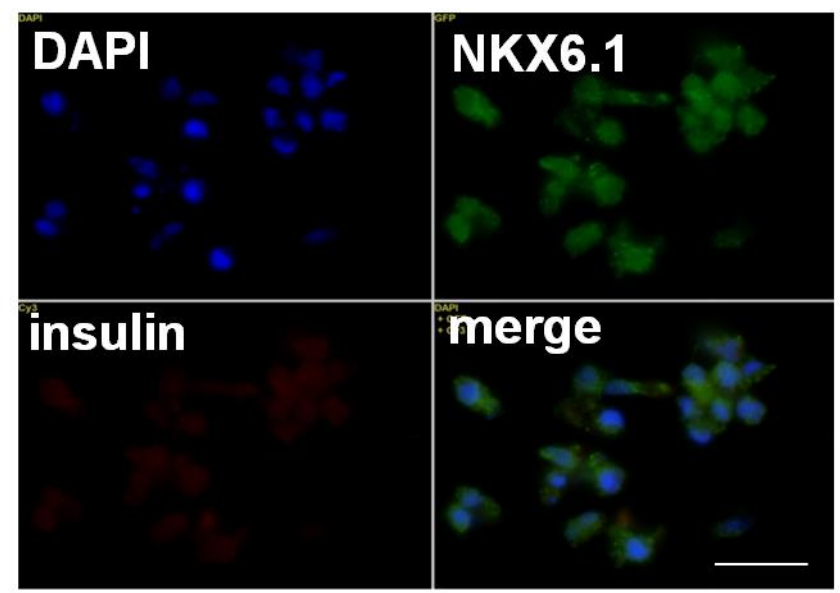

\section{SIRT1 Knockdown}

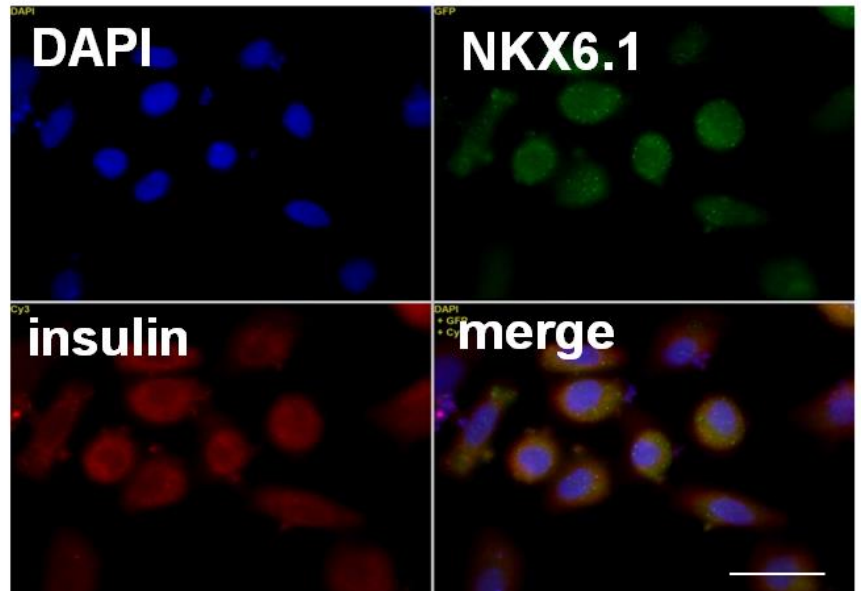

Fig. 3. The expression of insulin and Nkx6.1 in IPCs differentiated from control or SIRT1 shRNA expressing human ESCs. IPCs were differentiated from control or SIRT1 shRNA expressing human ESCs as described in "Materials and Methods". The cells were stained with anti-Nkx6.1 and anti-insulin antibodies, and Alexa 594 conjugated secondary antibody. The nuclei was stained with DAPI. IPCs, insulin-producing cells; ESCs, embryonic stem cells. 
SIRT1 shRNA expressing human ESCs compared to those from control shRNA expressing human ESCs (Fig. 4). These data suggest that SIRT1 knockdown enhances the functional differentiation of human ESCs into IPCs.

DTZ, a zinc-chelating agent, is known to selectively stain zinc in the insulin granule in pancreatic $\beta$ cells (Latif et al., 1988). SIRT1 knockdown enhanced the staining intensity in the clustered IPCs derived from human ESCs (Fig. 5). These data suggest that SIRT1 knockdown enhances insulin contents in human ESC-derived IPCs.

SIRT1 catalyzes the deacetylation of acetyl-lysine residues of p53 and inhibits its ability to transactivate genes such as p21cip1/waf1 (Vaziri et al., 2001). SIRT1 inhibits apoptosis induced by exogenous $\mathrm{H}_{2} \mathrm{O}_{2}$ through inhibition of p53 function to activate expression of proapoptotic genes (Kume et al., 2006). However, it has been demonstrated that SIRT1 has different effects in response to ROS which depends on the severity of stress (Han et al., 2008). SIRT1 acts as an apoptosis inducer, instead of a survival factor, at physiological levels of ROS (Han et al., 2008). In this study, we found that SIRT1 knockdown enhances the cluster size of human ESC derived $\beta$ cells. Thus SIRT1 knockdownenhanced increase in the cluster size of human ESCderived IPCs might be mediated by the anti-apoptotic effect of SIRT1.

It has been reported that SIRT1 positively regulates insulin secretion in pancreatic $\beta$ cells (Bordone et al., 2006). SIRT1 represses the uncoupling protein (UCP) gene UCP2 by binding directly to the UCP2 promoter. SIRT1mediated repression of UCP enhances ATP generation and increases insulin secretion by activation of voltage-gated $\mathrm{K}+\mathrm{ATP}$ channels. Thus although SIRT1 gene deletion enhances $\beta$ cell differentiation from human ESCs according to our data, there is a possibility that $\beta$ cells derived by SIRT1 gene deletion has a defect in insulin secretion. Thus, we suggest that SIRT1 should be transiently inhibited
MAFA

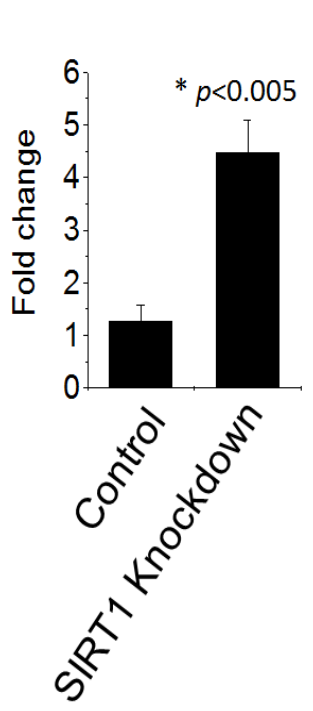

PDX1

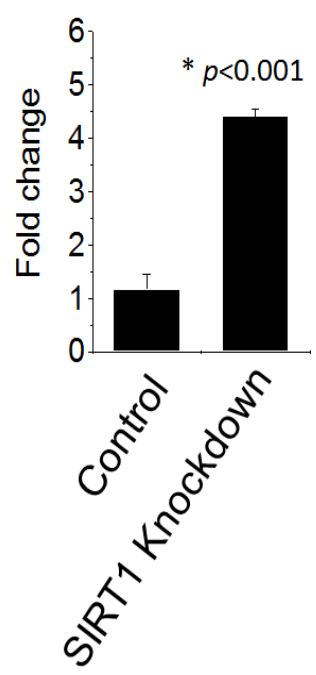

INS

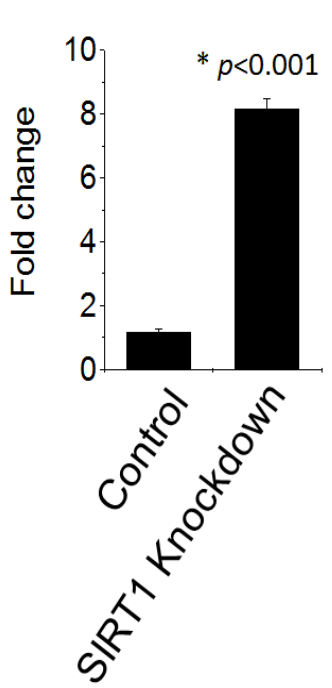

SST

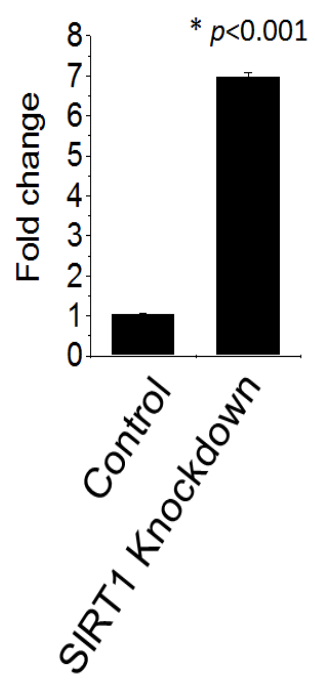

GCG

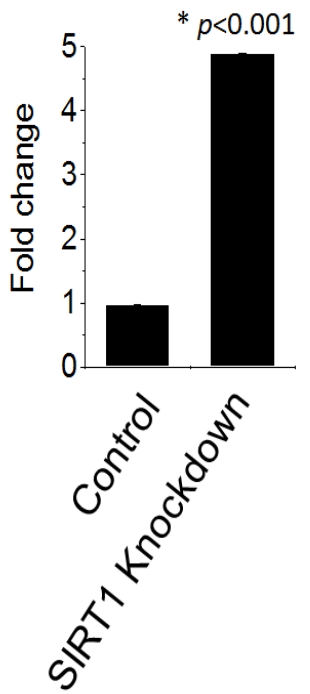

Fig. 4. mRNA expression levels of pancreatic genes in IPCs differentiated from control or SIRT1 shRNA expressing human ESCs. QRT-PCR was performed in IPCs differentiated from control or SIRT1 shRNA expressing human ESCs. The levels of MAFA, PDX1, INS, SST and GCG gene expression were determined. For each sample, the relative gene expression levels of IPCs from shRNA expressing human ESCs were normalized to corresponding levels in IPCs from control shRNA expressing hESCs. IPCs, insulin-producing cells; ESCs, embryonic stem cells; QRT-PCR, Quantitative real-time polymerase chain reaction. 
Control

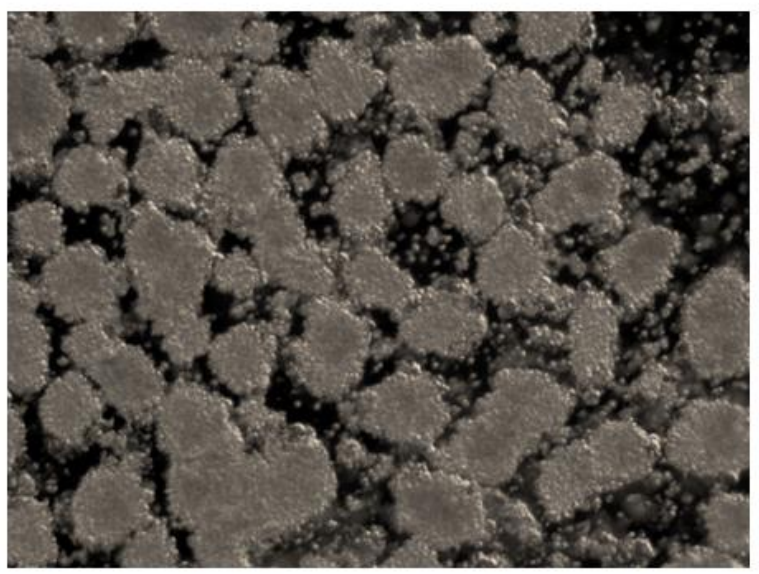

\section{SIRT1 Knockdown}

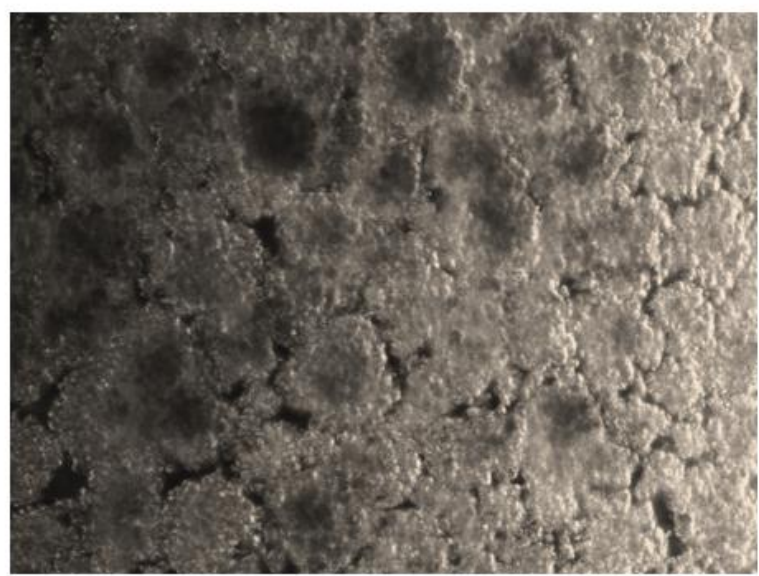

Fig. 5. The DTZ staining of IPCs differentiated from control or SIRT1 shRNA expressing human ESCs. IPCs were differentiated from control or SIRT1 shRNA expressing human ESCs as described in "Materials and Methods". IPCs were clustered and stained with DTZ as described in "Materials and Methods". DTZ, Dithizone; IPCs, insulin-producing cells; ESCs, embryonic stem cells.

during $\beta$ cell differentiation from human ESCs.

\section{ORCID}

Nan-Hee Seo

https://orcid.org/0000-0002-1404-8713

Hwa-Ryung Song

https://orcid.org/0000-0002-6424-7120

Myung-Kwan Han

https://orcid.org/0000-0001-5536-9778

\section{CONFLICT OF INTEREST}

The authors declare no potential conflict of interest.

\section{ACKNOWLEDGEMENTS}

This work was supported by the NRF grant (NRF2017M3A9B4065302) and the KRIBB/KRCF stem cell research initiative program (NAP).

\section{AUTHOR CONTRIBUTIONS}

Conceptualization: Han MK.

Data curation: Seo NH.

Formal analysis: Han MK. Seo NH.

Methodology: Seo NH, Song HR.

Investigation: Han MK

Writing-original daft: Song HR, Seo NH

Writing-review \& editing: Song HR, Han MK.

\section{ETHICS APPROVAL}

All experimental procedures involving hESCs were approved by the institutional review board of Jeonbuk National University (2014-07-023-002).

\section{REFERENCES}

Avalos JL, Bever KM, Wolberger C (2005) Mechanism of sirtuin inhibition by nicotinamide: Altering the $\mathrm{NAD}(+)$ cosubstrate specificity of a Sir2 enzyme. Mol Cell $17: 855-868$. 
Baur JA, Chen D, Chini EN, Chua K, Cohen HY, de Cabo R, Deng C, Dimmeler S, Gius D, Guarente LP, Helfand SL, Imai S, Itoh H, Kadowaki T, Koya D, Leeuwenburgh C, McBurney M, Nabeshima Y, Neri C, Oberdoerffer P, Pestell RG, Rogina B, Sadoshima J, Sartorelli V, Serrano M, Sinclair DA, Steegborn C, Tatar M, Tissenbaum HA, Tong Q, Tsubota K, Vaquero A, Verdin E (2010) Dietary restriction: Standing up for sirtuins. Science 329:1012-1013.

Bellin MD, Barton FB, Heitman A, Harmon JV, Kandaswamy R, Balamurugan AN, Sutherland DE, Alejandro R, Hering BJ (2012) Potent induction immunotherapy promotes long-term insulin independence after islet transplantation in type 1 diabetes. Am J Transplant 12:1576-1583.

Bordone L, Motta MC, Picard F, Robinson A, Jhala US, Apfeld J, Mcdonagh T, Lemieux M, Mcburney M, Szilvasi A, Easlon EJ, Lin SJ, Guarente L (2006) Sirt1 regulates insulin secretion by repressing UCP2 in pancreatic beta cells. PLOS Biol 4:e31.

Donmez G, Guarente L (2010) Aging and disease: Connections to sirtuins. Aging Cell 9:285-290.

Doss MX, Koehler CI, Gissel C, Hescheler J, Sachinidis A (2004) Embryonic stem cells: A promising tool for cell replacement therapy. J Cell Mol Med 8:465-473.

Haigis MC, Sinclair DA (2010) Mammalian sirtuins: Biological insights and disease relevance. Annu Rev Pathol 5:253-295.

Han MK, Song EK, Guo Y, Ou X, Mantel C, Broxmeyer HE (2008) SIRT1 regulates apoptosis and Nanog expression in mouse embryonic stem cells by controlling p53 subcellular localization. Cell Stem Cell 2:241-251.

Kroon E, Martinson LA, Kadoya K, Bang AG, Kelly OG, Eliazer S, Young $\mathrm{H}$, Richardson $\mathrm{M}$, Smart NG, Cunningham J, Agulnick AD, D'Amour KA, Carpenter MK, Baetge EE (2008) Pancreatic endoderm derived from human embryonic stem cells generates glucoseresponsive insulin-secreting cells in vivo. Nat Biotechnol
26:443-452.

Kume S, Haneda M, Kanasaki K, Sugimoto T, Araki S, Isono M, Isshiki K, Uzu T, Kashiwagi A, Koya D (2006) Silent information regulator 2 (SIRT1) attenuates oxidative stress-induced mesangial cell apoptosis via p53 deacetylation. Free Radic Biol Med 40:2175-2182.

Latif ZA, Noel J, Alejandro R (1988) A simple method of staining fresh and cultured islets. Transplantation 45:827830 .

Lumelsky N, Blondel O, Laeng P, Velasco I, Ravin R, Mckay R (2001) Differentiation of embryonic stem cells to insulin-secreting structures similar to pancreatic islets. Science 292:1389-1394.

Mao GH, Chen GA, Bai HY, Song TR, Wang YX (2009) The reversal of hyperglycaemia in diabetic mice using PLGA scaffolds seeded with islet-like cells derived from human embryonic stem cells. Biomaterials 30:17061714.

Nishikawa S, Jakt LM, Era T (2007) Embryonic stem-cell culture as a tool for developmental cell biology. Nat Rev Mol Cell Biol 8:502-507.

Rezania A, Bruin JE, Riedel MJ, Mojibian M, Asadi A, Xu J, Gauvin R, Narayan K, Karanu F, O'neil JJ, Ao Z, Warnock GL, Kieffer TJ (2012) Maturation of human embryonic stem cell-derived pancreatic progenitors into functional islets capable of treating pre-existing diabetes in mice. Diabetes 61:2016-2029.

Sander M, Sussel L, Conners J, Scheel D, Kalamaras J, Dela Cruz F, Schwitzgebel V, Hayes-Jordan A, German M (2000) Homeobox gene Nkx6.1 lies downstream of $\mathrm{Nkx} 2.2$ in the major pathway of beta-cell formation in the pancreas. Development 127:5533-5540.

Schisler JC, Fueger PT, Babu DA, Hohmeier HE, Tessem JS, Lu D, Becker TC, Naziruddin B, Levy M, Mirmira RG, Newgard CB (2008) Stimulation of human and rat islet beta-cell proliferation with retention of function by the homeodomain transcription factor Nkx6.1. Mol Cell Biol 28:3465-3476. 
Steiner DF, Cunningham D, Spigelman L, Aten B (1967) Insulin biosynthesis: Evidence for a precursor. Science 157:697-700.

Takahashi K, Yamanaka S (2006) Induction of pluripotent stem cells from mouse embryonic and adult fibroblast cultures by defined factors. Cell 126:663-676.

Thomson JA, Itskovitz-Eldor J, Shapiro SS, Waknitz MA, Swiergiel JJ, Marshall VS, Jones JM (1998) Embryonic stem cell lines derived from human blastocysts. Science 282:1145-1147.
Vaziri H, Dessain SK, Ng Eaton E, Imai SI, Frye RA, Pandita TK, Guarente L, Weinberg RA (2001) hSIR2 (SIRT1) functions as an NAD-dependent p53 deacetylase. Cell 107:149-159.

Wei R, Yang J, Hou W, Liu G, Gao M, Zhang L, Wang H, Mao G, Gao H, Chen G, Hong T. (2013) Insulinproducing cells derived from human embryonic stem cells: Comparison of definitive endoderm- and nestinpositive progenitor-based differentiation strategies. PLOS ONE 8:e72513. 